\title{
Numerical Simulation Of A Complete Low-Speed Wind Tunnel Circuit
}

\author{
Sudheer N. Nayani ${ }^{1}$, William L. Sellers, $\mathrm{III}^{2}$, Ana F. Tinetti ${ }^{3}$ \\ Analytical Services \& Materials, Inc. Hampton, VA 23666-1340 \\ Scott E. Brynildsen ${ }^{4}$ \\ Vigyan, Inc., Hampton, VA 23666-1325 \\ and \\ Eric L. Walker ${ }^{5}$ \\ NASA Langley Research Center, Hampton, VA, 23681-2199
}

\begin{abstract}
A numerical simulation of the complete circuit of the NASA Langley $14 \times 22-\mathrm{ft}$ low-speed wind tunnel is described. Inside the circuit, all turning vanes are modeled as well as the five flow control vanes downstream of the $1^{\text {st }}$ corner. The fan drive system is modeled using an actuator disk for the fan blades coupled with the fan nacelle. All the surfaces are modeled as viscous walls except the turning vanes, which were modeled as inviscid surfaces. NASA Langley's TetrUSS unstructured grid software was used for grid generation and flow simulation. Two turbulence models were employed in the present study, namely, the oneequation Spalart-Allmaras model and the shear stress transport (SST) model of Menter. The paper shows the flow characteristics in the circuit and compares the results with experimental data where available.
\end{abstract}

\section{Nomenclature}

$C_{p} \quad=$ pressure coefficient

$\mathrm{C} \quad=$ chord

$\mathrm{M} \quad=$ Mach number

$\mathrm{P}_{\text {set }} \quad=$ total pressure rise across the fan

$\mathrm{P}_{\mathrm{a}} \quad=$ ambient pressure

$\mathrm{P}_{\mathrm{s}} \quad=$ static pressure

$\mathrm{P}_{\mathrm{t}} \quad=$ total pressure

$\mathrm{P}_{\infty} \quad=$ reference static pressure

psf $\quad=$ pounds per squarefoot

$\mathrm{q}=$ dynamic pressure, $\frac{1}{2} \rho v^{2}$

$\mathrm{r}=$ radial distance along fan blade

$\mathrm{R}=$ fan blade tip radius

$\mathrm{T}_{\mathrm{t}}=$ total temperature

$\mathrm{T}_{\infty} \quad=$ reference static temperature

$\mathrm{u}, \mathrm{V}, \mathrm{W}=$ velocity components

$\rho \quad=$ fluid density

$\tau_{w} \quad=$ wall shear stress

\footnotetext{
${ }^{1}$ Senior Scientist, CFD Group, 107 Research Drive, Hampton, VA 23666-1340, AIAA Senior Member.

2 Senior Scientist, CFD Group, 107 Research Drive, Hampton, VA 23666-1340, AIAA Associate Fellow.

${ }^{3}$ Senior Scientist, CFD Group, 107 Research Drive, Hampton, VA 23666-1340, AIAA Senior Member.

${ }^{4}$ Research Engineer, GeoLab, 30 Research Drive, Hampton, VA 23666-1325.

${ }^{5}$ Chief Engineer for Test Operations Excellence, Research Directorate, AIAA Associate Fellow
} 


$$
\begin{aligned}
\mathrm{u}^{+} & =\text {dimensionless velocity, } u^{+}=u / u_{\tau} \\
u_{\tau} & =\text { friction velocity, } \sqrt{\tau_{w} / \rho} \\
\mathrm{y}^{+} & =\text {dimensionless wall distance } \frac{y u_{\tau}}{v} \\
v & =\text { kinematic viscosity } \\
\mathrm{W} & =\text { width of the cross section for nondimentionalization }
\end{aligned}
$$

$\begin{array}{ll}\text { Abbreviations } \\ \text { BC } & =\text { Boundary condition } \\ \text { CAD } & =\text { Computer-aided design } \\ \text { CFD } & =\text { Computational fluid dynamics } \\ \text { FCV } & =\text { Flow control vanes } \\ \text { GIS } & =\text { Geographic Information Systems } \\ \text { Sta. } & =\text { Tunnel station, ft. } \\ \text { TV } & =\text { Turning vanes } \\ 14 \times 22 & =14 \times 22-\mathrm{ft} \text { low-speed wind tunnel }\end{array}$

\section{Introduction}

rom the early days of the Wright Brothers, wind tunnels have been used to explore the physics of fluid flow and $\Gamma$ to predict the performance of air vehicles. Wind tunnels of today span the range from incompressible to hypersonic flows, and include unique facilities like high Reynolds number, cryogenic tunnels. To predict the flight performance of an air vehicle using these facilities requires an in-depth knowledge of the characteristics of the facility and the methods used to correct the wind tunnel results to better simulate free-air conditions.

Wind tunnel wall corrections ${ }^{1}$ have been around for a long time and include techniques to account for the constraining effect of the walls on the streamlines in the tunnel, blockage effects from the model and support systems, and buoyancy corrections for any longitudinal or streamwise variations in static pressure in the tunnel. In most cases, simplified geometry representations of the test section were used in the modeling of these corrections. In fact, early simulations used infinitely long representations of the test section with simplified inviscid wall boundary conditions, and the test article and support system were represented by potential flow singularities. These earlier linear methods begin to fail for large models (from either blockage or lift) that are in relative proximity to the test section boundaries. Newer wall correction methods have been developed that use arrays of wall pressures to help mitigate these effects; however, many of these newer methods still employ potential flow singularity models.

Future aerospace vehicles will be much more integrated to enable reduced fuel burn, noise, and emissions. The best attributes of modeling, simulation, and experiment will be required to successfully evaluate the performance of these vehicles. Computational fluid dynamics (CFD) is already making significant inroads in the vehicle design process, but experimental data from wind tunnel facilities are still needed to validate the CFD methods and to examine off-cruise conditions. To validate CFD methods, experiments must be completely simulated and that may include modeling tunnel walls, model support systems, or any other features that may affect the wind tunnel data. Wind tunnel operations, flow characteristics, and wall corrections must also be truly understood. The experimentalist must understand and appreciate what is needed to provide the proper boundary conditions and data for CFD simulations in the most accurate way possible.

Modeling and simulation can aid in the design of new and the modification of existing facilities. In the past, wind tunnels were designed using prior experience and empirical guidelines ${ }^{2}$. The successful application of CFD to wind tunnel facility analysis would allow for the design of more efficient facilities and the development of better modifications of existing facilities to improve their efficiency and expand their capability. Presently, portions of the circuit, such as a diffuser ${ }^{3}$, are being analyzed with CFD to improve tunnel efficiency and characteristics.

A review of published literature has turned up attempts to model the high-speed leg of a wind tunnel. These cases have been performed to provide information on test section flow anomalies. Most notable are the work of Olander ${ }^{4}$ and Wall ${ }^{5}$, where they modeled the high-speed leg of the Volvo Slotted Wall Wind Tunnel. The purpose of the effort was to try to identify the cause of an asymmetric pressure distribution on the tunnel walls. They modeled the entire first leg of the Volvo tunnel from the settling chamber to the first diffuser. In their model, extensions were added to the entrance of the settling chamber and exit of the first diffuser to create a buffer for the CFD boundaries. Valuable insight was gained on flow through wall slots and boundary layer removal interaction with models in the test section. The cause for the asymmetric pressure distribution could not be identified and it was 
speculated that the entire circuit would need to be simulated to capture the history of the flow traveling through the circuit before entering the settling chamber.

Two cases where the simulation of an entire wind tunnel circuit has been attempted were also found. Generation of a computational grid for a complete tunnel circuit is a very difficult process and these two cases were directed at boundary layer wind tunnels designed for wind engineering studies. This type of facility has unique requirements for simulating atmospheric boundary layers and their effect on buildings and structures, and is configured differently from conventional aerodynamic performance wind tunnels. Bertholds ${ }^{6}$ provided simulations to support the development of a new University of Sydney Boundary Layer Tunnel. The fan was modeled by two separate parts: an inlet of constant velocity and an outlet of constant velocity. This technique allows one to select a fixed flow velocity out of the fan without concern for the incoming flow. He also modeled the turning vanes in the corners and screens in the contraction. Moonen ${ }^{7}$ simulated the flow in the Jules Verne Climatic Wind Tunnel that was being considered for providing data for wind loads on buildings. He proposed a methodology for utilizing a single "fan" boundary condition. He modeled the larger and wider spaced guide vanes in the corners and the large wood lattice "screen" in the contraction. The screens used in atmospheric boundary layer tunnels are very different compared to the wire-mesh anti-turbulence screens used in the aerodynamic performance wind tunnel. In addition, the spacing between the guide vanes used in the boundary layer tunnel is much larger than that used in the closely spaced turning vanes found in the aerodynamic tunnel. Both Bertholds and Moonen were concerned with large atmospheric type boundary layers; thus, the viscous spacing corresponded to $\mathrm{y}^{+}$values of $\sim 100$, as compared to the $\mathrm{y}^{+}$values of one that are required for conventional aerodynamic performance wind tunnels.

In the past, an in-depth knowledge of the facility characteristics meant calibrating the tunnel, which may include measurements of the longitudinal variation of static pressure in the test section, measurements of free stream turbulence, and flow angularity at different locations in the test section. Depending on the facility there might be a few discrete stations where measurements of boundary layer profiles were obtained on the floor or the walls. In the larger facilities, the measurement of flow variations in cross-sections of the test section is problematic and expensive so only limited data exist.

\section{A. Selection of a Test Facility}

The CFD methodology for this task will require extensive calibration of the CFD results with experimental data. This is a step-by-step development process so that the importance of geometric modeling, grid generation, boundary conditions and fan drive modeling can be assessed. The selection of a candidate facility for comparison with the simulations was the first step in the process.

\section{1. $14 \times 22-f t$ Low-Speed Wind Tunnel Description}

The 14 x 22-ft low-speed wind tunnel (14x22), shown in Figure 1, was constructed in 1969 to provide an improved understanding of the aerodynamics of vertical/short takeoff and landing (V/STOL) configurations. The tunnel is a closed circuit, atmospheric wind tunnel with a maximum flow velocity in the test section of $338 \mathrm{ft} / \mathrm{sec}$ (q 130 psf). The test section, which is $50 \mathrm{ft}$ long, can be operated in either a conventional closed configuration or in an open configuration (sometimes described as 3/4 open) by raising the ceiling and sidewalls to form a floor-only configuration. A 9-bladed, $40 \mathrm{ft}$ diameter fan coupled to a 12,000 hp electric motor powers the tunnel. Figure 2 shows a schematic representation of the tunnel, including some of the stations throughout the circuit. Tunnel station 0.0 and 50.0 are the entrance and exit of the test section, respectively, and tunnel station 192 is the exit of the first diffuser. Tunnel station 17.75 is at the center of the forward turntable in the test section and is where models are typically located. The facility had two anti-turbulence screens when the tunnel was originally built. Presently, the tunnel has 4 anti-turbulence screens and a honeycomb in the settling chamber. There is also a porous grid at the exit of the $4^{\text {th }}$ diffuser (approximately station 550). Tunnel station 7.87 is the location where measurements of the wall boundary layers were taken during Test 509 just prior to the $1^{\text {st }}$ AIAA High Lift Workshop ${ }^{8}$. The reference $(\mathrm{x}, \mathrm{y}, \mathrm{z})$ coordinate system for the simulations included in this paper is located on the centerline of the tunnel circuit at station 0.0. Gentry ${ }^{9}$ et al. provide a complete description of the tunnel and examples of its flow characteristics. 


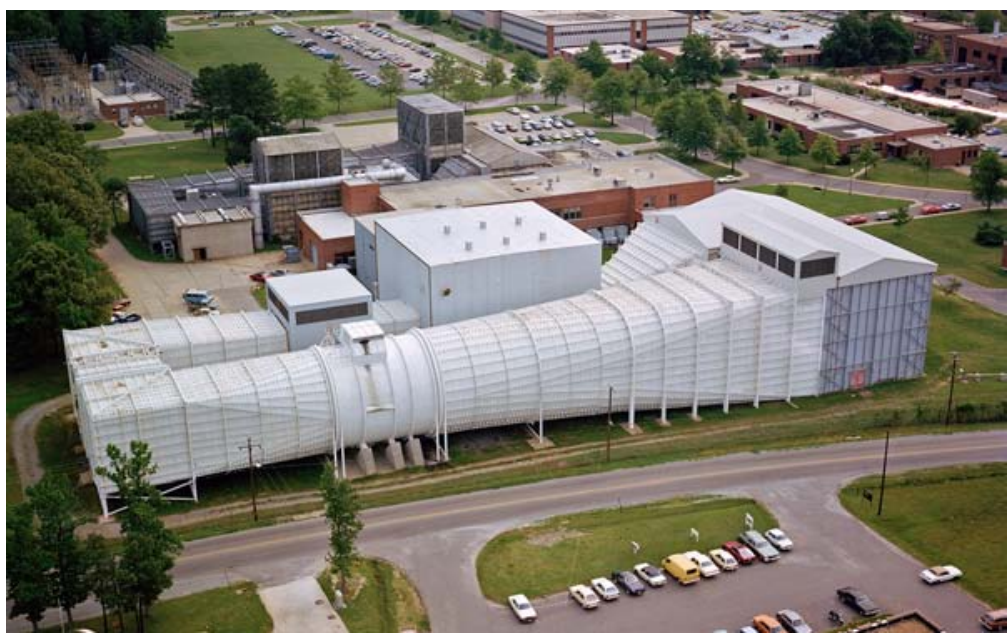

Figure 1 Aerial view of the 14 x 22-ft Low-Speed Wind Tunnel (circa 1981).

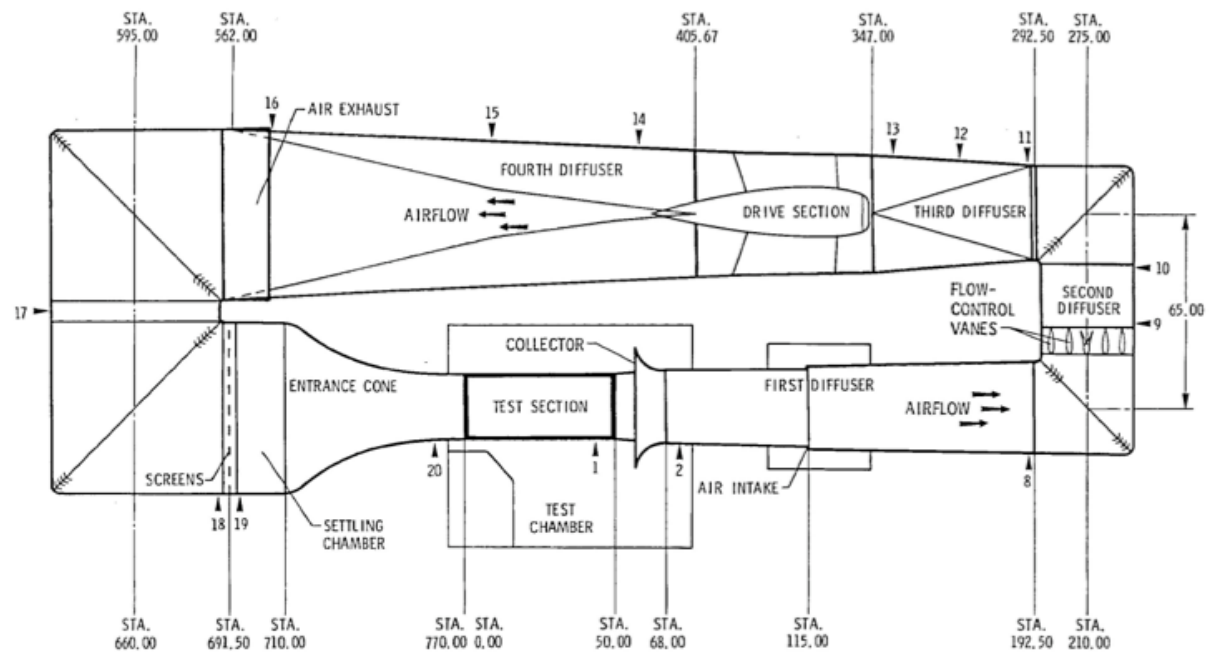

Figure 2 Wind tunnel schematic showing tunnel components and stations, and velocity traverse stations (circa1981), where small numbered icons show the flow traverse locations $(1-20)$

\section{Tunnel Modifications and Flow Improvements}

The tunnel had operational and flow quality issues when it came on line in the early 1970s. The design operating speed could not be reached and the tunnel operated with this limited speed capability for approximately 10 years. In the early1980s, the tunnel was equipped with a dedicated laser velocimetry (LV) system. Operation of the LV system requires seed particles, released into the flow in the settling chamber, whose motion is recorded as they pass through the desired measurement station in the test section. It was noticed early on that when seed particles were needed on the tunnel centerline, they had to be introduced near the inside corner wall of the settling chamber. These two issues, reduced speed capability and flow asymmetry in the tunnel circuit, prompted an investigation by the facility staff on tunnel flow quality and ways to improve it.

The $14 \times 22$ is unique in that over the years it has undergone a series of flow improvement studies. To design the improvements, it was necessary to obtain extensive flow measurements throughout the entire circuit ${ }^{10,11}$. These included horizontal and vertical flow velocity measurements on the centerline of the tunnel circuit and static pressure (wall pressures) throughout the circuit.

The static pressure measurements were instrumental in locating the blockage in the tunnel circuit that reduced the maximum flow velocity in the test section. The blockage was caused by a debris screen that was installed, floor to ceiling, on the turning vanes of the $2^{\text {nd }}$ corner. The screen, which was 4 times more dense than specified in the design, was replaced with a more porous screen that only reaches $1 / 4$ of the height of the turning vanes. Once the debris screen was replaced, the flow velocity in the test section reached the design operating speed. 
The flow surveys were crucial in discovering that the flow in the return leg of the tunnel was highly asymmetric due to a large separated flow region in the $4^{\text {th }}$ diffuser. There was also a flow asymmetry in the $2^{\text {nd }}$ diffuser just behind the flow control vanes. This asymmetry was mitigated by the addition of trailing edge flaps on the flow control vanes that pushed the flow back toward the inner wall and presented a more uniform flow to the entrance of the fan. It was found that the flaps also reduced the extent of flow separation in the $4^{\text {th }}$ diffuser. A final flow improvement study was completed in the mid 1980s. This project replaced the existing 2 anti-turbulence screens with 4 screens and a honeycomb. A large screen or "grid" was placed at the exit of the $4^{\text {th }}$ diffuser. The grid was made of $1 / 4$ inch thick steel plate with 2 -inch square holes. The flow quality modifications dropped the turbulence levels in the tunnel test section such that the u-component of velocity fluctuations was below $0.1 \%$ at all tunnel speeds.

In 2014 NASA Langley undertook the task of laser scanning several of their highly used facilities to document their present geometric condition. The $14 \times 22$ wind tunnel was selected and the laser point cloud data has been utilized to provide a comparison between construction drawings (as designed) and point cloud (as built) geometry. No information has been found on the design of the $40 \mathrm{ft}$. diameter fan, which complicates setting the boundary condition for the actuator disk modeling the fan.

\section{B. Preparatory Work for this Study}

Nayani ${ }^{12}$ et al. simulated the high-speed leg of the NASA Langley $14 \times 22-\mathrm{ft}$ low-speed wind tunnel as part of a buildup in capability to the present work. Reference 12 provided a comparison between two different sources of geometry for the facility. The first was based on construction drawings that were turned into a CAD description of the "as-designed" geometry. A laser-scanning technique was used to provide surface measurements of what was described as the "as-built" geometry. Comparisons were made between simulated flow and tunnel calibration data. A limited comparison between two different flow solvers was also performed. The results showed that the "asdesigned" geometry was acceptable for preliminary assessment of a facility, but if one was interested in determining wall corrections or tunnel asymmetries the "as-built" geometry was far superior.

This paper will describe the effort undertaken to extend the work of Nayani et al. to include the entire closed circuit of the $14 \times 22$ facility. The simulation will include the tunnel shell, turning vanes, flow control vanes, and fan drive nacelle. Results from different turbulence models will be compared with experimental data when available. The paper will help address the importance of the "full tunnel" effect on the flow through the tunnel circuit that was raised in the earlier high-speed leg only simulations.

\section{Numerical Modeling Approach}

The computations presented in this paper were obtained using the NASA Tetrahedral Unstructured Software System $^{13}$ (TetrUSS), developed at the NASA Langley Research Center (LaRC). The system is comprised of several loosely integrated software packages that allow the user to start with a geometry, typically in a CAD or Plot3D format, then generate surface grids and tetrahedral volume grids for use with the flow solver. The surface definition and geometry setup package GridTool ${ }^{14}$ is used to set up surface patches, boundary conditions, and viscous spacing requirements. The volume grid software package VGRID takes the files from GridTool and uses the Advancing Layers Method ${ }^{15}$ (ALM) to generate thin-layered viscous cells for the viscous part of the grid, and the Advancing Front Method ${ }^{16}$ (AFM) to generate the inviscid field cells.

The Reynolds averaged Navier-Stokes code USM3D, described in reference 13, was used for the computations presented in this paper. USM3D is a cell-centered, upwind-biased, finite volume flow code that solves the compressible Euler and Navier-Stokes equations on tetrahedral unstructured grids. The computations were performed using 512 processors on the Pleiades Supercomputer at NASA Ames Research Center. Steady, fully viscous flow solutions using the Spalart-Allmaras (SA) and shear stress transport (SST) ${ }^{17}$ turbulence models were obtained for comparison with the wind tunnel data.

Table 1 summarizes the test conditions for the simulations. The target dynamic pressure and Mach number in the test section are shown along with the unit Reynolds number. The Reynolds number for the $\mathrm{q}=57.25 \mathrm{psf}$ simulation was $1.4113 \times 10^{6}$ per $\mathrm{ft}$, or $123.84 \times 10^{6}$ based on the $87.75 \mathrm{ft}$ run length from the start of the contraction to tunnel station 17.75 . The $\mathrm{q}=57 \mathrm{psf}$ and $68 \mathrm{psf}$ conditions correspond, respectively, to the velocity survey and pressure distribution data from References 10 and 11. 
Table 1 Test conditions for simulations

\begin{tabular}{|l|l|l|}
\hline Target q, psf & Mach number, Sta $=17.75$ & $\mathrm{Rn} / \mathrm{ft}$ \\
\hline 100 & 0.2678 & 1.7108 \\
\hline 68.69 & 0.2139 & 1.5207 \\
\hline 57.25 & 0.1923 & 1.4113 \\
\hline
\end{tabular}

\section{Geometry Development}

NASA Langley is embarking upon a process to define the geometry of several of the Center's heavily used facilities. The data obtained will serve two purposes: 1) provide a detailed description of the "as-built" condition of the facility that can be used to track changes over time, and 2) provide a digital geometric description that can serve to develop computational grids at a later date.

The GIS team at NASA Langley used laser-scanning techniques to provide surface measurements accurate to within one centimeter throughout the 14 x 22 -ft tunnel circuit. The point cloud obtained for the closed test section configuration contained approximately 159 million points for the high-speed leg and 587 million points for the entire circuit. The point cloud was transferred to the GeoLab group at NASA Langley to process the data into surfaces to be used for grid generation purposes.

The GeoMagic ${ }^{\circledR}$ software program was used to manually down-sample the point cloud to a particular entity of interest (e.g. test section), and features that were not relevant for this work were excluded (e.g. windows, doors). A best-fit plane/cylinder shape was fit to the points of interest and deviations were checked to determine if additional points should be added or removed. This process was repeated until a satisfactory fit was obtained. The resulting surface was imported into the Uniqraphics ${ }^{\circledR}$ CAD program to match the new surface to adjacent features. The Unigraphics surfaces were then imported back into GeoMagic to check the deviations from the scanned points. This process was iterated until surfaces suitable for grid generation were obtained.

The laser-scanned surfaces provide details that were not readily available in the construction drawings. A fairing in the contraction that smooths the flow over the mounting hardware for the honeycomb and screens was identified. A $300 \mathrm{ft}$ radius on the ceiling at several stations in the tunnel circuit was also identified, as well as the transitions from the flat to curved ceilings. Most of the deviations between the construction drawings and scanned surfaces were on the order of one centimeter.

\section{Boundary Conditions (BC)}

The selection and application of the appropriate boundary conditions was an integral part of this study. Two different methods of driving the flow in the closed tunnel circuit were investigated based on the boundary conditions used to simulate the fan propeller or drive. Because design data for the fan could not be located, values for the various boundary conditions used in the present simulations had to be iterated until the desired Mach number in the test section was obtained.

1. Jet $B C$

To use the jet boundary conditions, two planes placed a short distance apart were located in the tunnel circuit at the approximate position of the tunnel fan. These planes split the circuit so that it was no longer continuous. The jet engine exhaust boundary condition (102) of the USM3D flow solver was set on the downstream plane by defining the total pressure and total temperature. The jet engine intake (101) boundary condition was set on the upstream plane. To simulate the total pressure rise across the fan, an initial pressure $\left(\mathrm{p}_{\text {set }}\right)$ was chosen for BC 102 and iterated until the desired target Mach number was reached at tunnel station 17.75 .

\section{Actuator Disk BC}

USM3D includes an actuator disk boundary condition to simulate the aggregate effects of a propeller or rotor. It has primarily been used for external flow simulations of propeller driven vehicles or helicopters. The propeller boundary condition requires the use of a specialized procedure for generating volume grids around zero-thickness surfaces. The actuator disk consists of two distinct zero-thickness surfaces collapsed on each other. The upstream surface acts as an inflow boundary condition (501) and the downstream surface acts as an outflow boundary condition (502). The upstream $501 \mathrm{BC}$ extrapolates tangential velocity $\mathrm{V}_{\mathrm{t}}, \mathrm{P}, \rho$. The downstream $502 \mathrm{BC}$ produces a jump in pressure and imparts a swirl to the flow. The pressure and swirl jump conditions are derived from the input values of thrust and torque coefficients, respectively. Either a uniform or radially varying thrust or torque condition can be specified. If the torque coefficient is set to zero, as was done for these simulations, no swirl is imparted to the flow. In the long run, the actuator disk will provide a much more accurate representation of the fan drive so only the results from using the actuator disk BC are shown below. 


\section{E. Development of the Computational Grids}

Figure 3 shows the surfaces that were provided by GeoLab, obtained from the laser-scanned point-cloud data. The corner turning vanes, flow control vanes, fan drive section, and curvature on the various ceiling segments were all captured. The discontinuity in the first diffuser lines caused by the inlet flaps are faired to create a smooth transition with the downstream portion of the first diffuser. The exhaust port at the end of the $4^{\text {th }}$ diffuser was also closed.

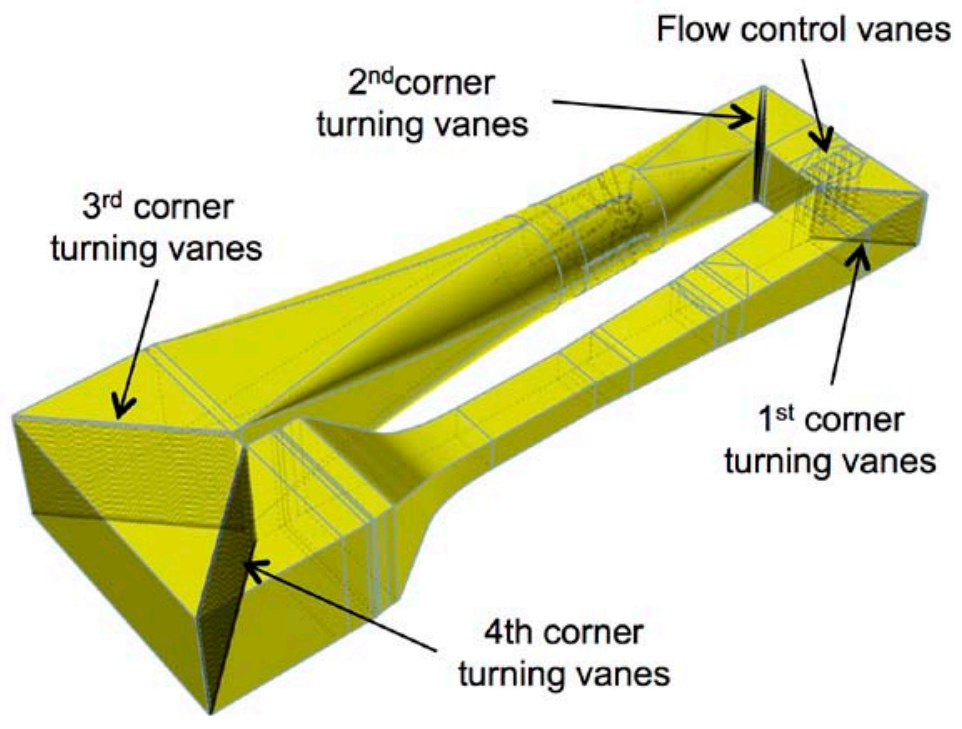

Figure 3 IGES CAD file of the complete circuit

From these CAD surfaces, the patching process to produce a watertight geometry, and the sourcing to generate an appropriately dense surface and volume grid was begun. The viscous grids were based on the target conditions shown in Table 1. Generating the single-block unstructured grid took months of considerable effort.

Two tunnel configurations were considered. The first is the "empty tunnel" configuration, and includes the tunnel shell, the flow control vanes, and the fan drive nacelle. The second configuration adds the turning vanes in the four corners.

\section{F. Empty Tunnel Configuration}

This configuration was used primarily to investigate use of the actuator disk and jet boundary conditions to drive the flow in the circuit. A grid for the empty tunnel with an actuator disk was completed, consisting of 199 patches and approximately 75 million tetrahedral elements. Viscous, steady flow conditions were used in the circuit during the initial attempt to simulate the aerodynamic characteristics of the empty tunnel. We fully expected the flow to have large separation and recirculation regions because no turning vanes were modeled that would aid the flow in negotiating the sharp 90 degree turns.

Figure 4 shows the surface grid for the empty tunnel configuration. The actuator disk is placed at the location of the fan blades. The empty tunnel configuration was successful in demonstrating that the actuator disk was capable of driving the flow in the circuit when provided with the proper thrust value for the boundary condition. Note that the fan drive nacelle support struts were not modeled. Because fan design point information could not be located, specifying only the thrust for the actuator disk BC provides a uniform pressure jump with no swirl velocity. Although not shown here, the nacelle support struts (vanes) are cambered to remove swirl caused by the fan. Since the flow out of the actuator disk has no swirl, inclusion of the support struts would generate regions of flow separation that do not occur during tunnel operation. The struts will be included when we are able to derive the thrust and torque characteristics by reverse engineering the fan design.

An attempt was also made to drive the flow in the empty tunnel configuration with the jet BC. Getting a solution was problematic in that the delta $\mathrm{P}_{\mathrm{t}}$ for the $102 \mathrm{BC}$ had to be set at an artificially high value just to overcome the initial flow resistance. Setting the artificially high $\mathrm{P}_{\mathrm{t}}$ overcame the resistance and drove the flow in the circuit, but made the flow in the test section transonic with local regions of supersonic flow in the $1^{\text {st }}$ diffuser. Once the flow was circulating in the right direction the value of $\mathrm{P}_{\mathrm{t}}$ was reduced and then iterated to obtain the target Mach number. 


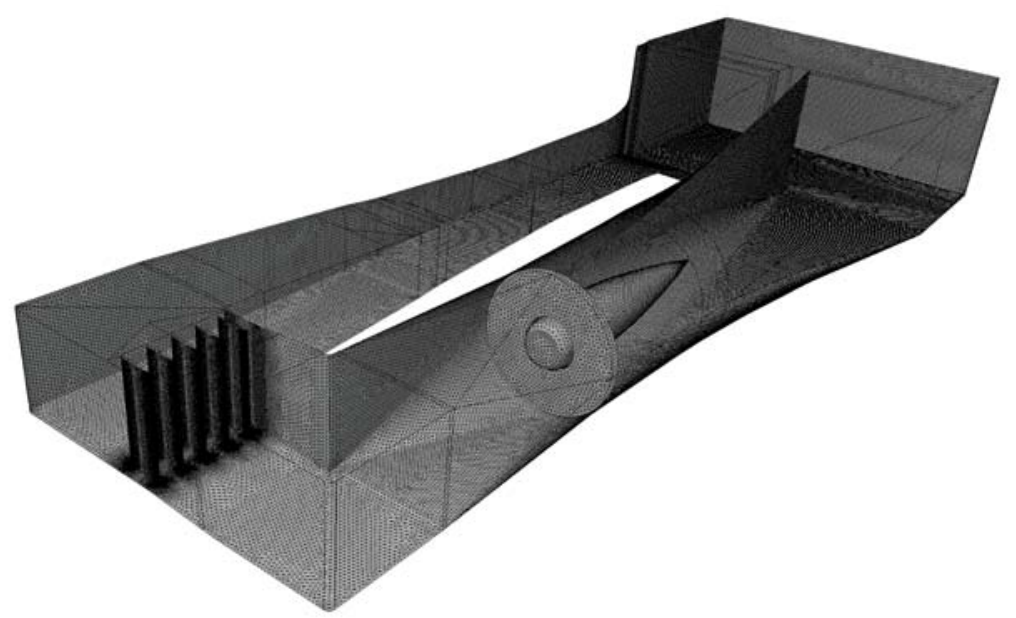

Figure 4 Empty tunnel surface grid with an actuator disk

\section{G. Complete Tunnel Configuration}

The grid for this case was extremely challenging and tested the limits of the TetrUSS grid generation system. It includes the tunnel shell, five flow control vanes, 410 turning vanes, fan drive nacelle, and the actuator disk. A full viscous grid would be very large ranging on the order of hundreds of millions of tetrahedra. At this stage of the investigation, the complete circuit was modeled with viscous surfaces except for the turning vanes, which were modeled with inviscid walls to keep the grid size reasonable. Generating the single-block unstructured grid took months of effort. The grid contained over 2600 surface patches and approximately 11,000 curves. The present simulations do not include fan stator vanes, honeycomb, nor the anti-turbulence screens. The configuration used in this study resembles the 1985 configuration of the 14x22 tunnel except for the 2 anti-turbulence screens.

Figure 5 through Figure 9 show an overall view of the surface grid for the complete tunnel and highlight the various regions in the tunnel circuit. The full tunnel grid contains approximately 89 million tetrahedral cells based on a $\mathrm{y}^{+}$of $\sim 0.5$.

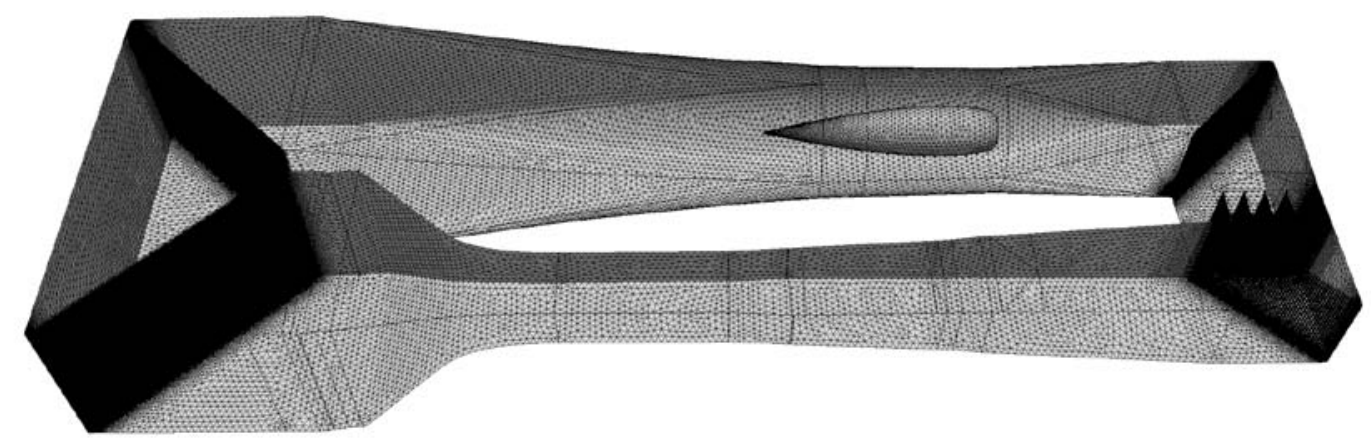

Figure 5 Overall view of tunnel surface grid 


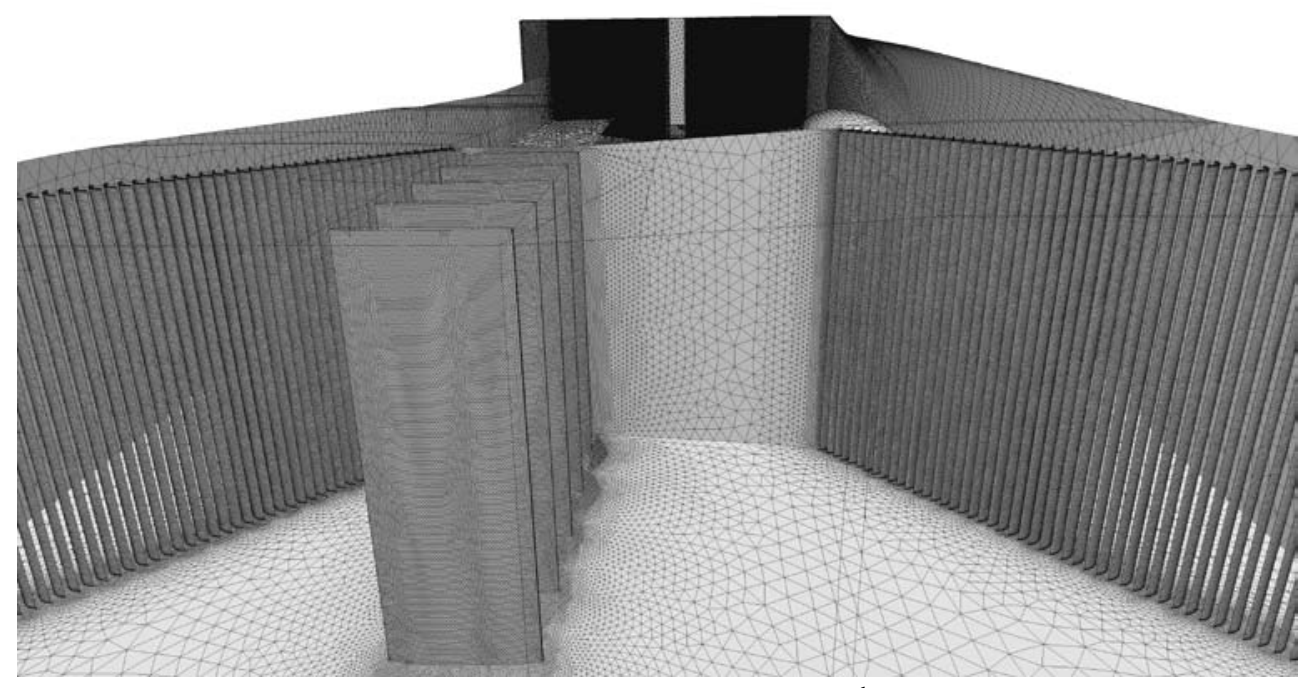

Figure 6 View of the surface grid for the $1^{\text {st }}$ and $2^{\text {nd }}$ corner turning vanes

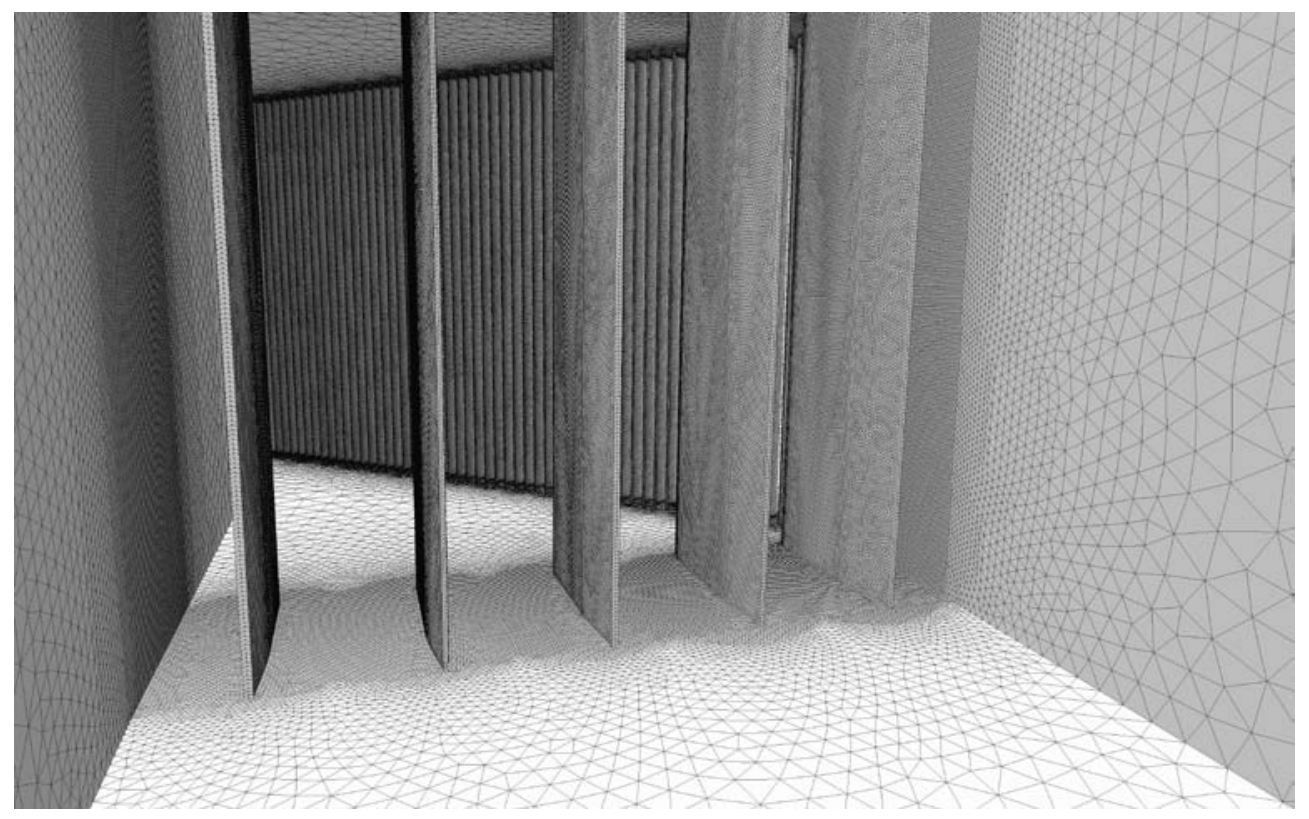

Figure 7 View of the surface grid looking upstream of the flow control vanes 


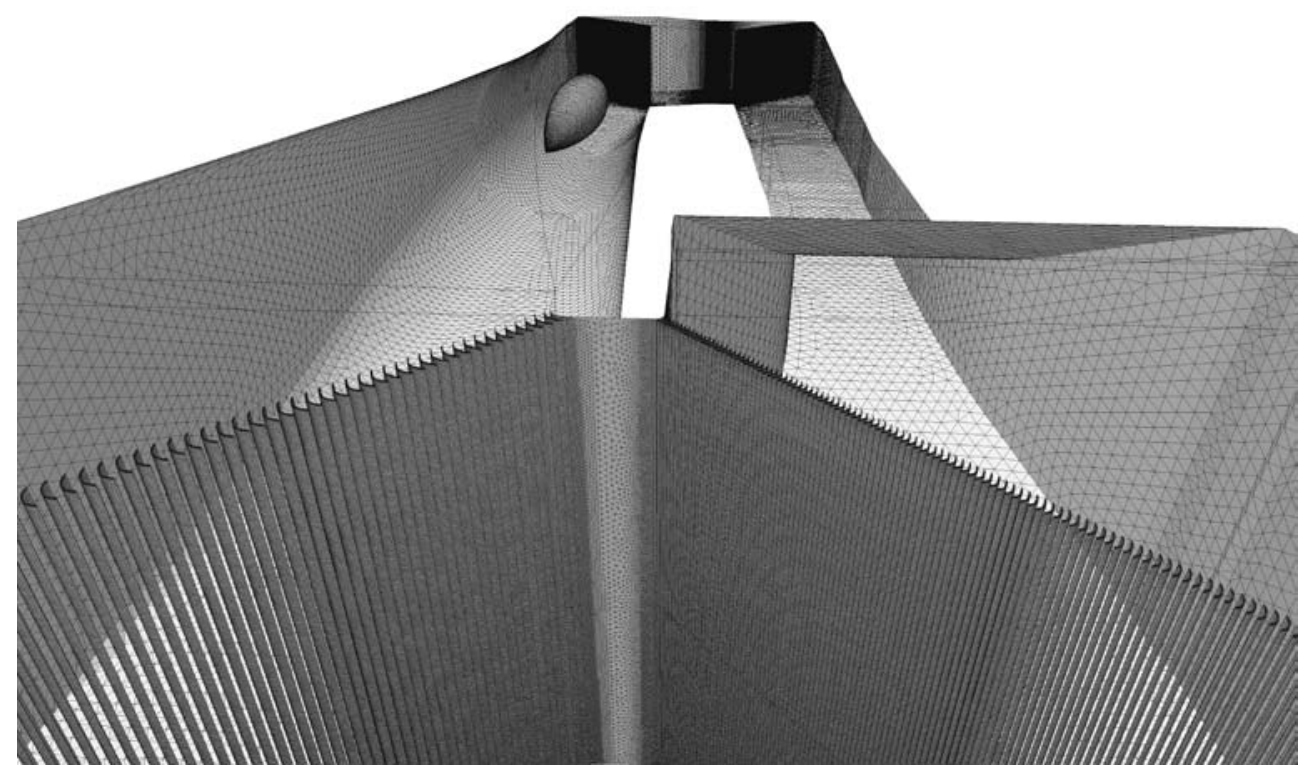

Figure 8 Overall view of the surface grid of the $3^{\text {rd }}$ and $4^{\text {th }}$ corner turning vanes

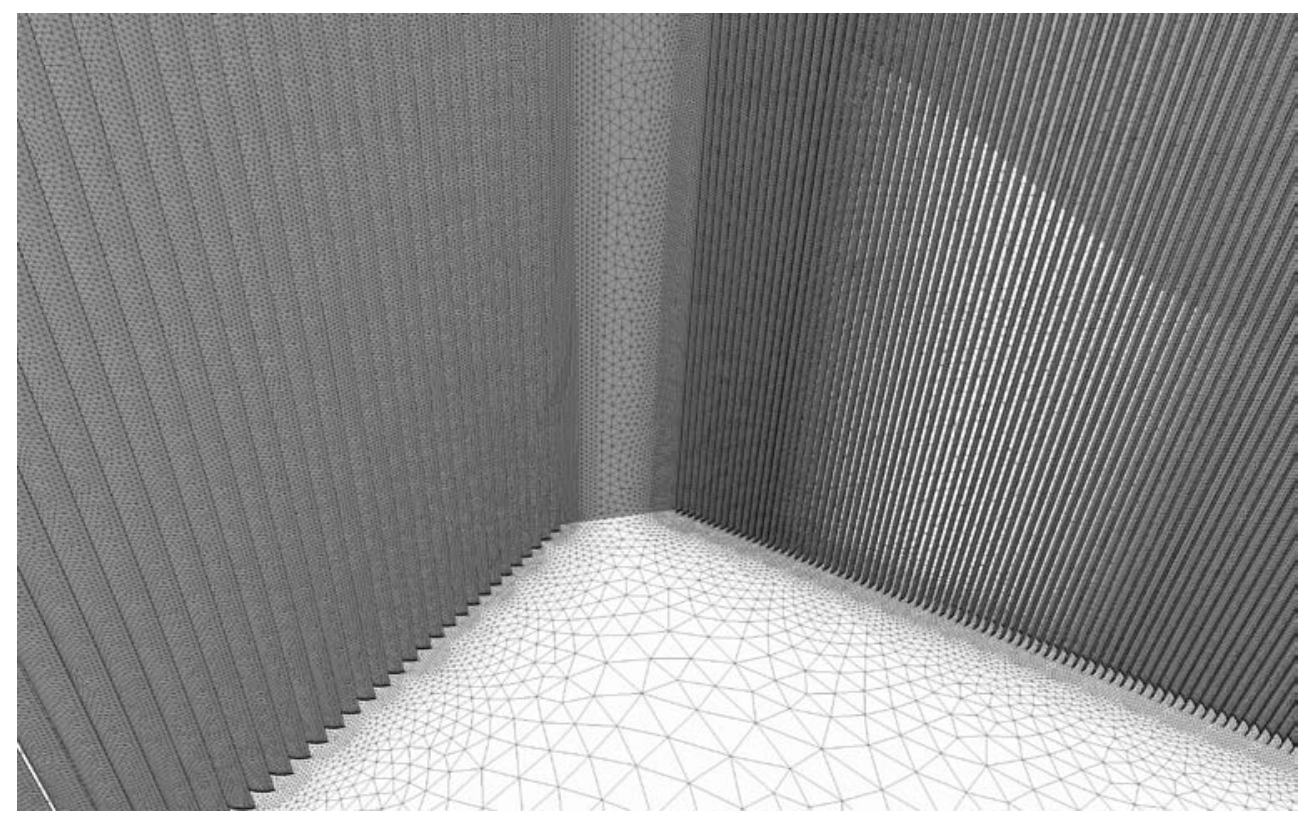

Figure 9 Close up view of the surface grid and the $3^{\text {rd }}$ and $4^{\text {th }}$ corner turning vanes

\section{Results}

Since the simulations are based on a configuration that resembles the tunnel circa 1983, the predicted flow behavior will more closely represent the experimental data of Reference 10. The results presented in this paper will focus on a steady-state solution obtained using the two-equation SST turbulence model. A limited comparison with results obtained with the one-equation Spalart-Allmaras turbulence model will be shown also. The solutions were developed by iterating the thrust coefficient for the actuator disk until a target Mach number or dynamic pressure in the test section was obtained. Reference 10 did not provide the actual tunnel conditions (i.e. Mach number, q) so those values were approximated.

Figure 10 through Figure 12 show contours of the Mach number and total and static pressures on a horizontal plane situated on the tunnel centerline at $\mathrm{z}=0.0 \mathrm{ft}$. Note from Figure 10 that the flow smoothly accelerates through the contraction and the test section. About midway down the first diffuser a velocity defect starts to build up and is 
skewed toward the outer wall of the diffuser. The simulations predict regions of reverse flow on the inner wall beginning at the $2^{\text {nd }}$ diffuser and continuing through the fan drive and the fourth diffuser. The flow in the $4^{\text {th }}$ diffuser is highly separated and skewed toward the outer wall. The total pressure contours in Figure 11 clearly show the regions of higher pressure losses on the walls of the $1^{\text {st }}$ through the $3^{\text {rd }}$ diffusers. Figure 11 also depicts the jump in total pressure caused by the actuator disk at the fan drive nacelle. Figure 12 presents the static pressure distribution through the tunnel circuit and the pressure jump across the actuator disk. Although these figures are enlightening in that they depict overall flow behavior within the circuit, they do not provide an indication of how realistic are the results. It was both important and fortunate that the flow surveys throughout the $14 \times 22$ circuit were acquired in 1983 (ref. 10).
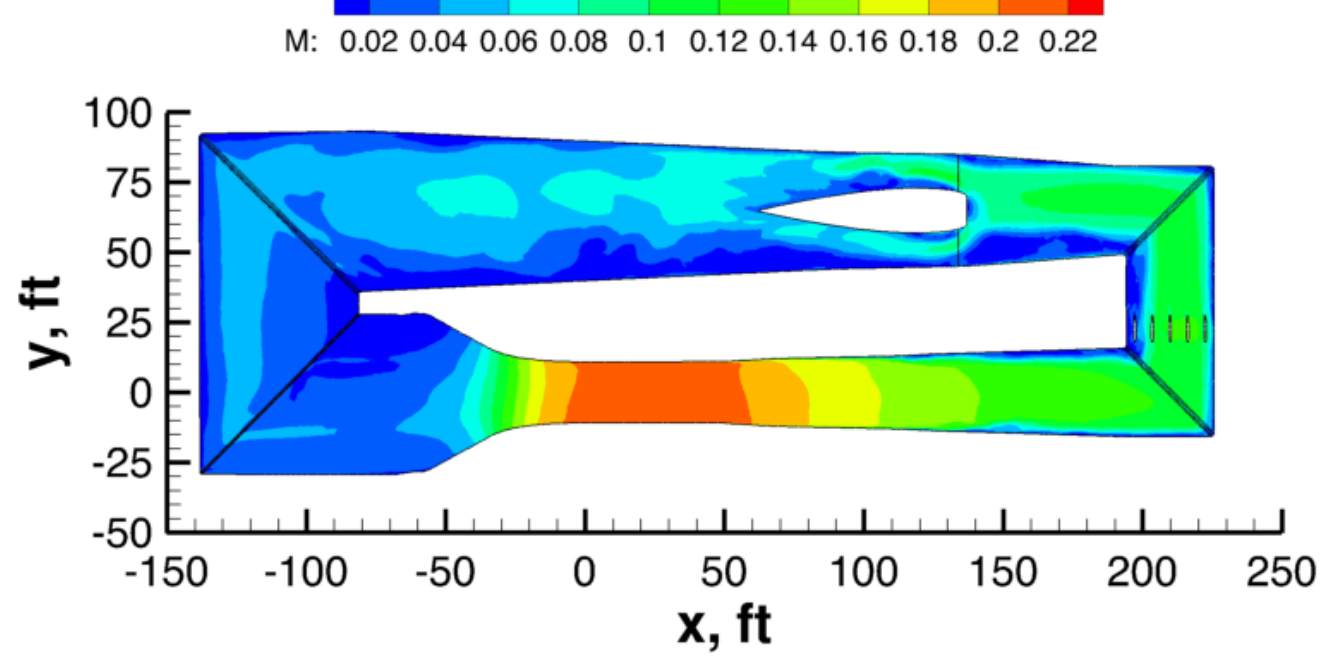

Figure 10 Simulated Mach number contours, $\mathrm{z}=0.0 \mathrm{ft}$, $\mathrm{q}_{\infty}=57.25 \mathrm{psf}$, (circa 1983 flow lines)
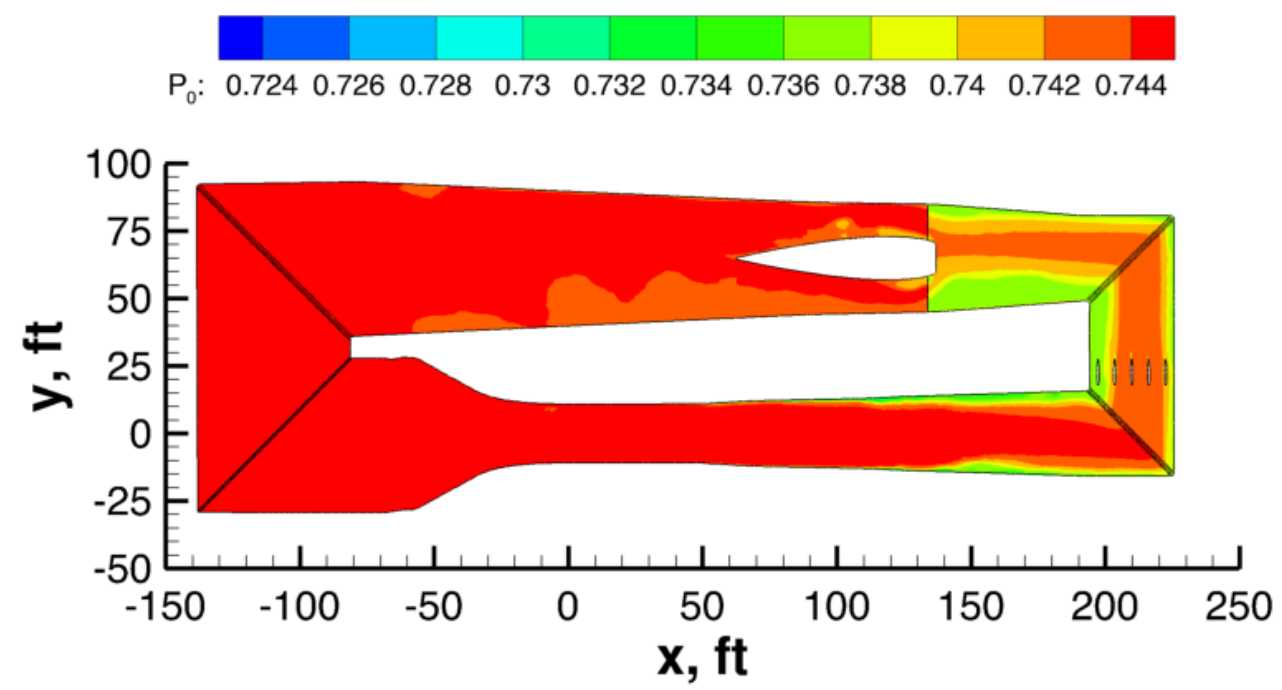

Figure 11 Simulated total pressure contours, $\mathrm{z}=0.0 \mathrm{ft}$, $\mathrm{q}_{\infty}=57.25 \mathrm{psf}$, (circa 1983 flow lines) 


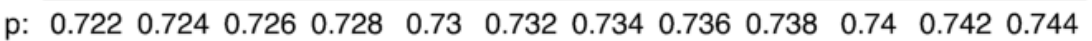

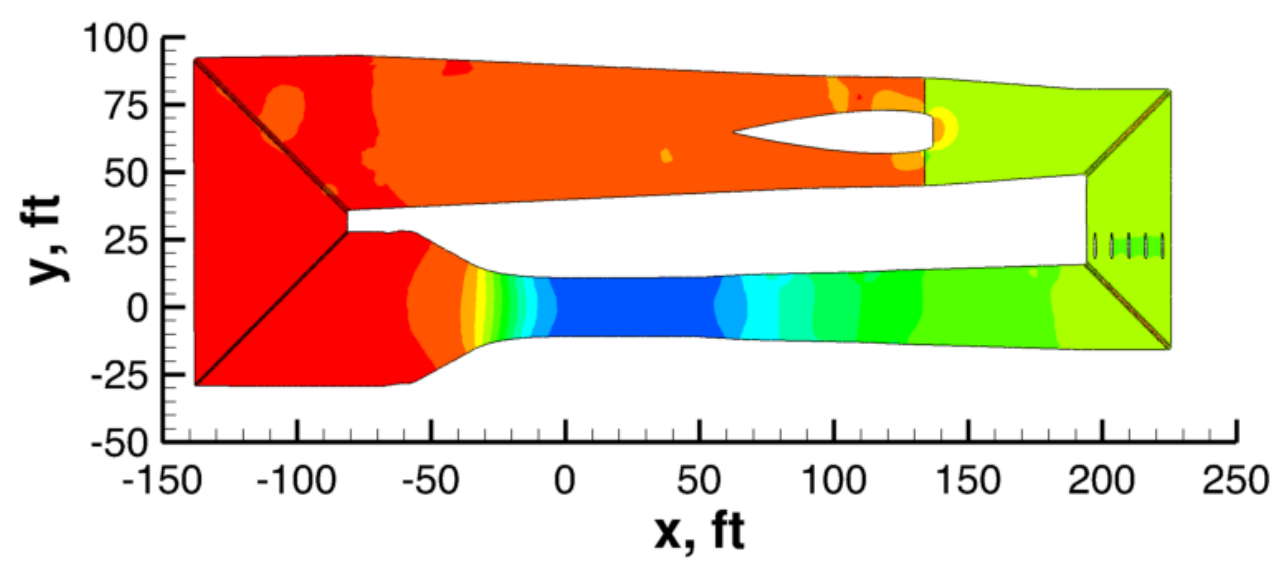

Figure 12 Simulated static pressure contours, $\mathrm{z}=0.0 \mathrm{ft}, \mathrm{q}_{\infty}=57.25 \mathrm{psf}$.

Figure 13 compares measured and simulated velocity profiles in the high-speed leg of the tunnel. Figure 13a depicts the profile at station 1 , which is located near the exit of the test section. Both profiles indicate that a uniform velocity distribution exists at that location. The experimental results show a slight skew toward the outer wall that is not picked up in the simulations. Figure $13 \mathrm{~b}$ compares the profiles at station 8 , which is near the exit of the $1^{\text {st }}$ diffuser. The simulations show a velocity defect on the walls and a nearly uniform profile in the potential core region. The experimental results show a much larger skew of the profile with a larger shear layer on the inner wall.

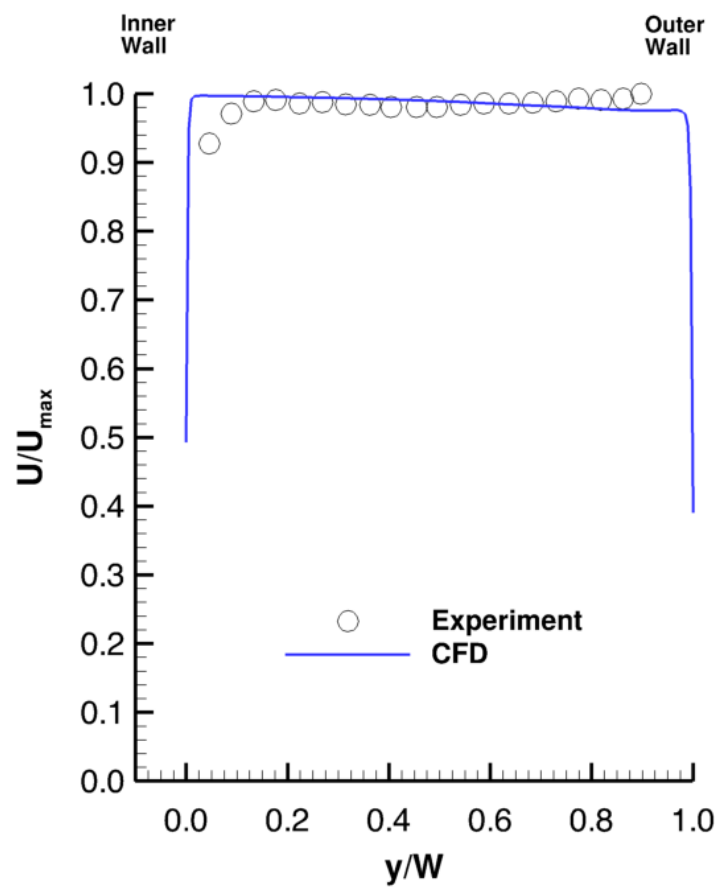

a) Station 1

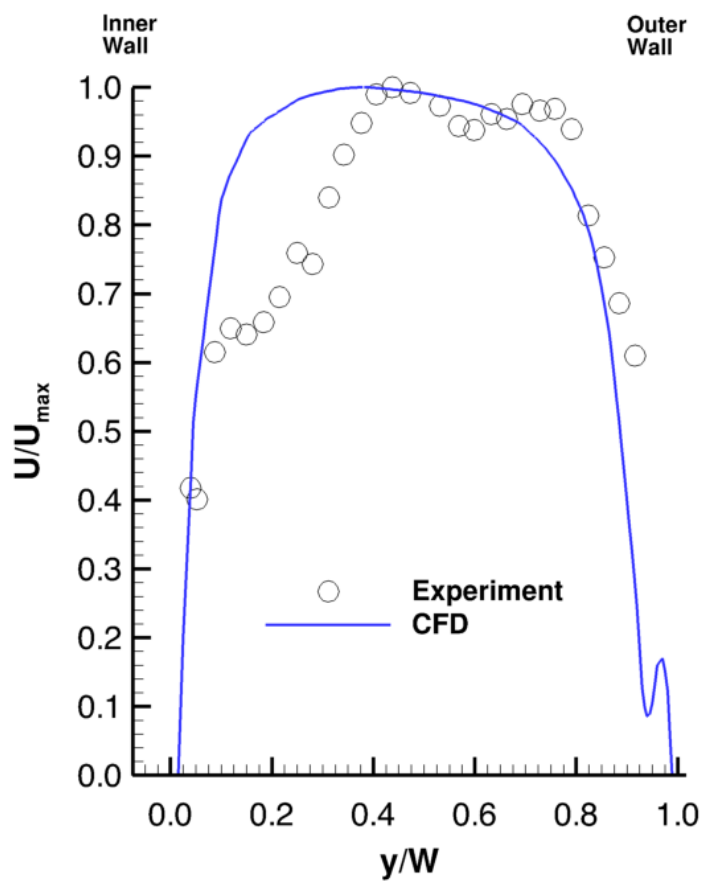

b) Station 8

Figure 13 Horizontal velocity profiles, high-speed leg, q = 57.25 psf

Figure 14 shows a comparison of the measured and simulated velocity profiles in the $2^{\text {nd }}$ leg of the tunnel, which includes the $2^{\text {nd }}$ diffuser and flow control vanes (FCV). Figure 14a shows the velocity profile at Station 9 . The wakes generated by 4 of the 5 FCVs are clearly seen in the simulated profile of Figure 14a. The experimental measurements only capture the wakes of the two inner FCVs. Both experimental and simulated profiles show that 
the flow is skewed toward the outer wall of the tunnel circuit. Figure 14b presents the velocity profile at station 10, which is located at the exit of the $2^{\text {nd }}$ diffuser. Both experimental and simulated profiles indicate the presence of a well defined potential core that is skewed toward the outer wall. The measured profile is fuller near the inner wall than the simulated results. The simulations show a region of flow separation near the inner wall.

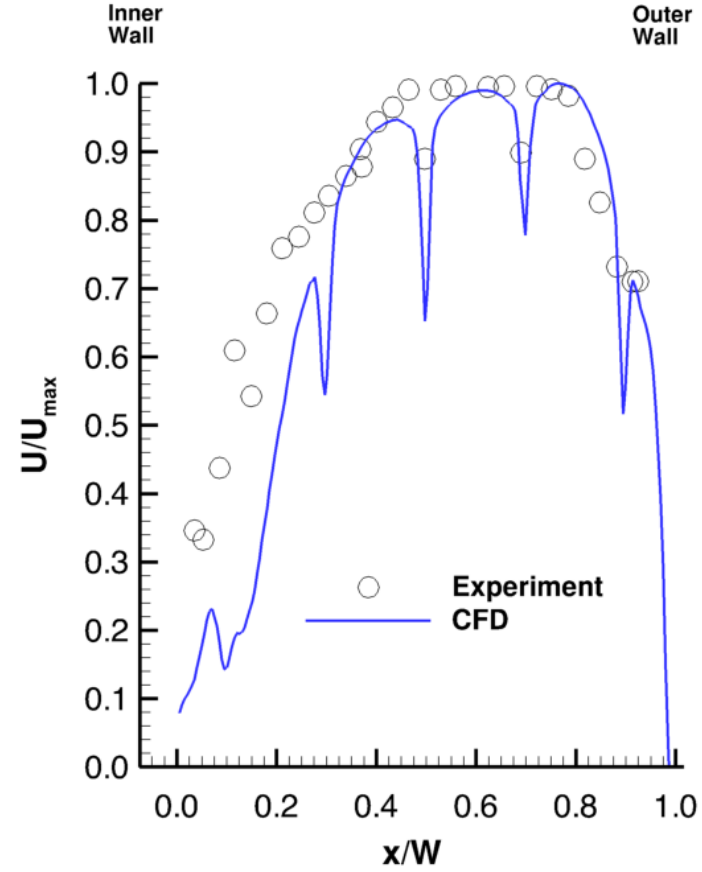

a) Station 9

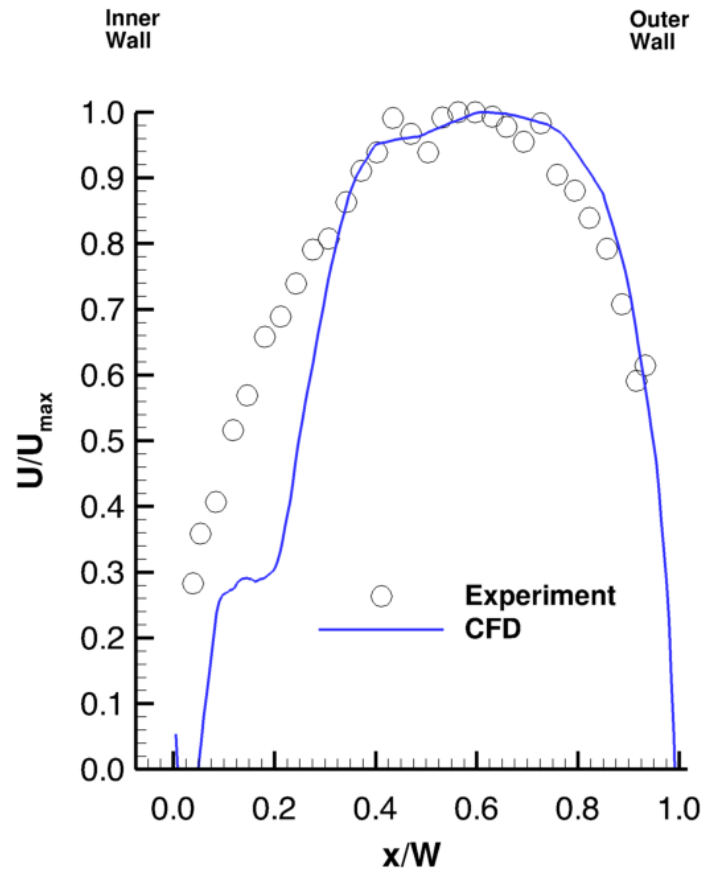

b) Station 10

Figure 14 Horizontal velocity profiles, cross leg including the $2^{\text {nd }}$ diffuser, $q=57.25$ psf

The results for the return leg are shown for general interest only, as they require further study for a number of reasons. First and foremost, the fan stator vanes were not modeled; thus, their effect on flow behavior was not simulated. In addition, the actuator disk requires better and more complete input. If fan design information cannot be found in the archives, then the fan needs to be "reverse engineered" from the construction drawings to provide torque data, and spanwise distributions of thrust and torque on the fan blades. Only after this information is available, an accurate simulation of the flow impinging on, and convecting past, the fan blades can be generated..

Figure 15 compares measured and simulated velocity profiles in the return leg of the tunnel. The two stations shown are in the $3^{\text {rd }}$ diffuser, downstream of the $2^{\text {nd }}$ corner. Figure 15a depicts the profiles at station 11, which is located at the entrance to the $3^{\text {rd }}$ diffuser. Both simulated and measured profiles are smooth and exhibit only a slight skew toward the outer wall. The simulations indicate that a region of reverse flow exists near the inner wall of the tunnel. Figure 15b shows the profiles at station 13 , which is located at the exit of the $3^{\text {rd }}$ diffuser, slightly upstream of the fan section. At this station, the experimental and simulated results differ markedly. The simulations predict a velocity profile with a well defined potential core entering the fan section, whereas the experimental data show a profile with two skewed peaks. The difference is believed to be caused by improper definition of the incoming flow, as the actuator disk is only provided a thrust value for the boundary condition. That means that a uniform jump in properties would be produced across the fan. Without an input value for torque, there is no swirl component to the flow. 


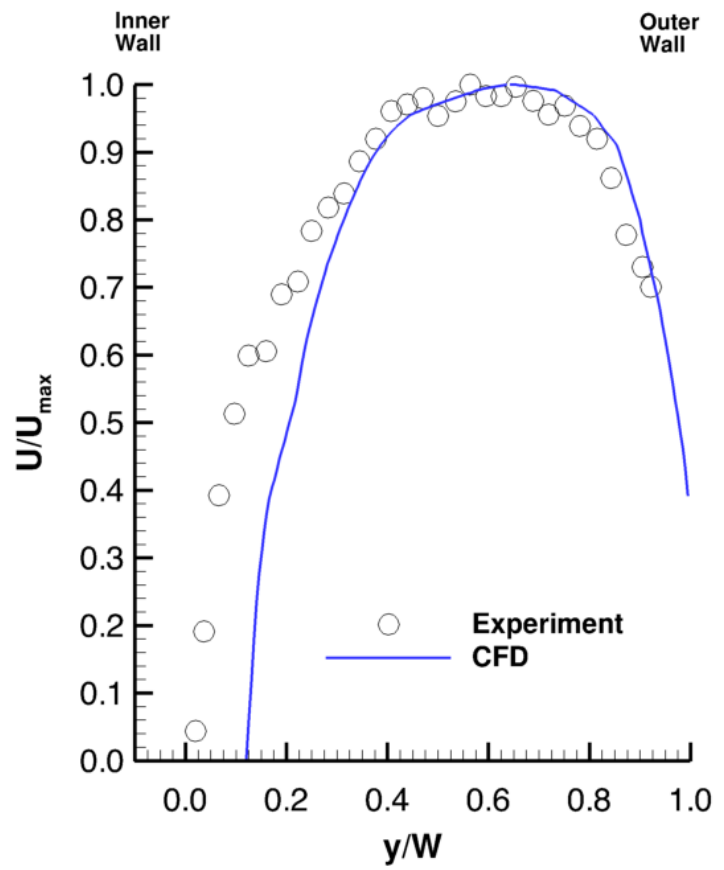

a) Station 11

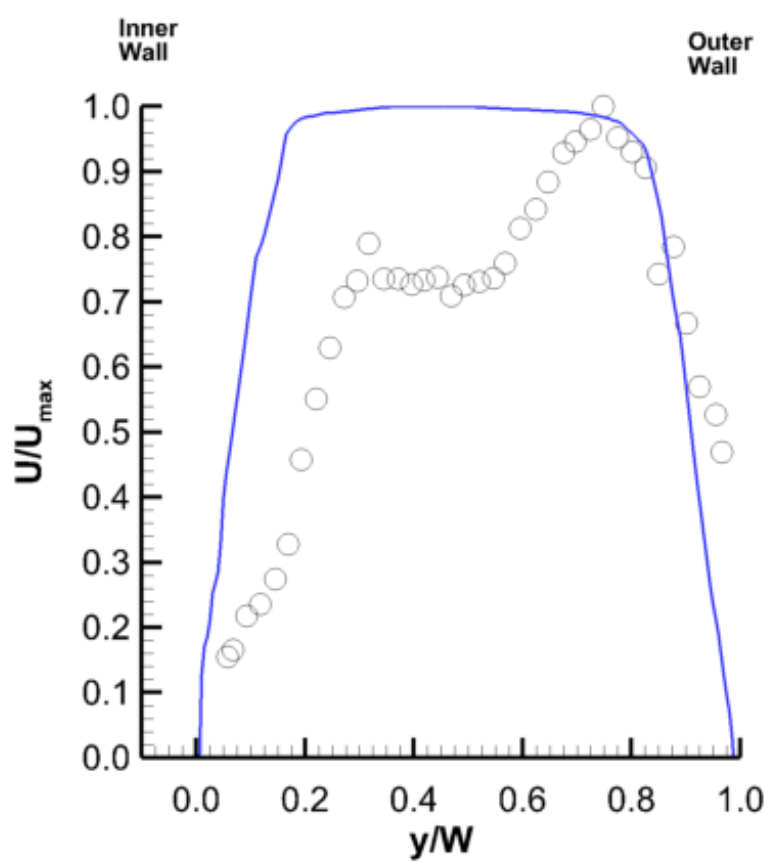

b) Station 13

Figure 15 Horizontal velocity profiles, return leg including the $3^{\text {rd }}$ diffuser, $q=57.25$ psf

Figure 16 shows a comparison of the measured and simulated velocity profiles in the return leg of the tunnel. The two stations are in the $4^{\text {th }}$ diffuser, downstream of the fan drive section. Figure 16a depicts information at station 14, which is slightly downstream of the fan drive nacelle. Both the experimental and simulated results show a profile with two peaks, but the simulated profile is skewed toward the outside wall and shows a large region of reverse flow near the inner wall. Figure $16 \mathrm{~b}$ shows the profiles at station 16 , which is located at the exit of the $4^{\text {th }}$ diffuser. At this distance behind the fan, the peaks have subsided and the profile is smooth but skewed toward the outer wall. The simulated profile is fuller and shows a region of reverse flow on the inner wall, whereas the experimental results show the reverse flow on the outer wall.

Figure 17 presents a comparison between measured and predicted static pressure distributions around the tunnel circuit. The experimental data were digitized from the figures appearing in Reference 9. The CFD static pressures correspond to the tunnel centerline, whereas the experimental pressures were acquired at ports located on both inside and outside walls of the tunnel. The predicted pressures follow the measured values very closely through the contraction, test section and first diffuser. The predicted distribution captures the spike present in the vicinity of the flow control vanes ( sta 240), but its magnitude is not as high as that of the measured data. The predicted pressure rise across the fan is not as strong as the measured values and pressures downstream of the fan do not match. This behavior is expected, since the swirl characteristics of the fan, or the fan stators, are not modeled. 


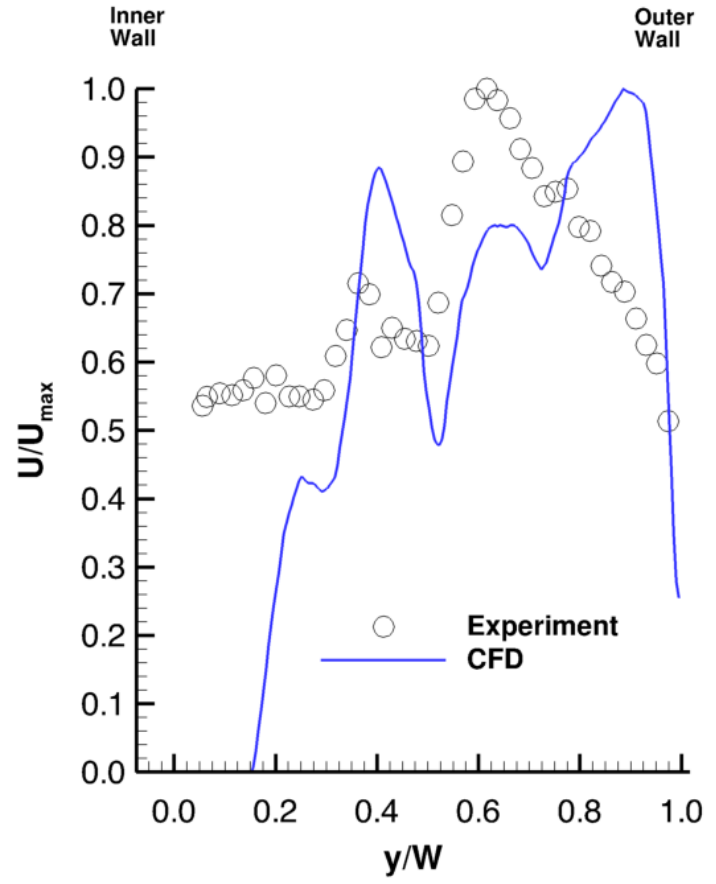

a) Station 14

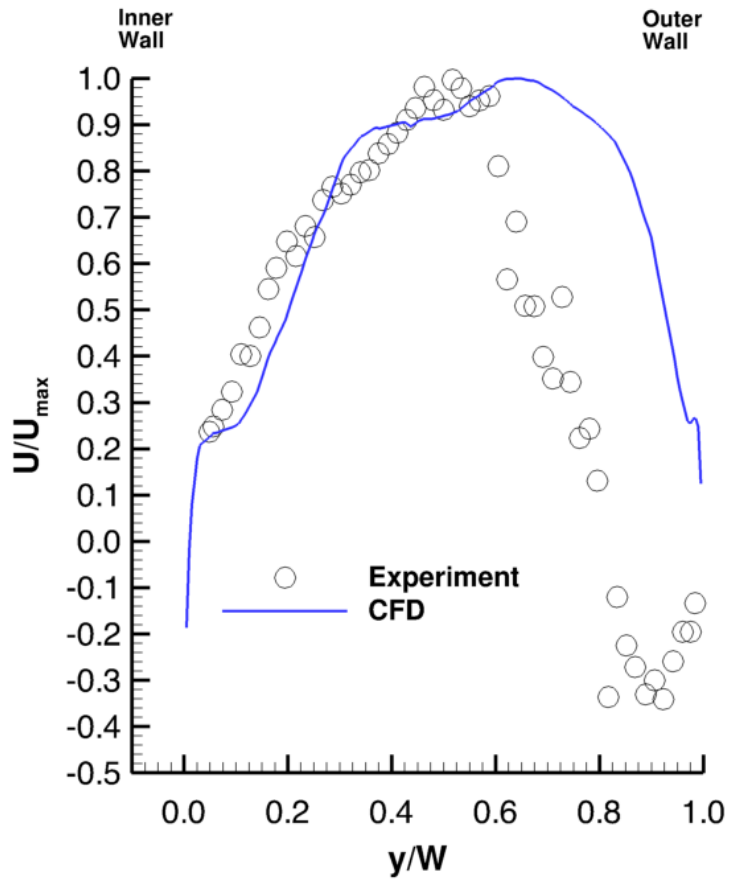

b) Station 16

Figure 16 Horizontal velocity profiles, return leg, $4^{\text {th }}$ diffuser, $q=57.25$ psf

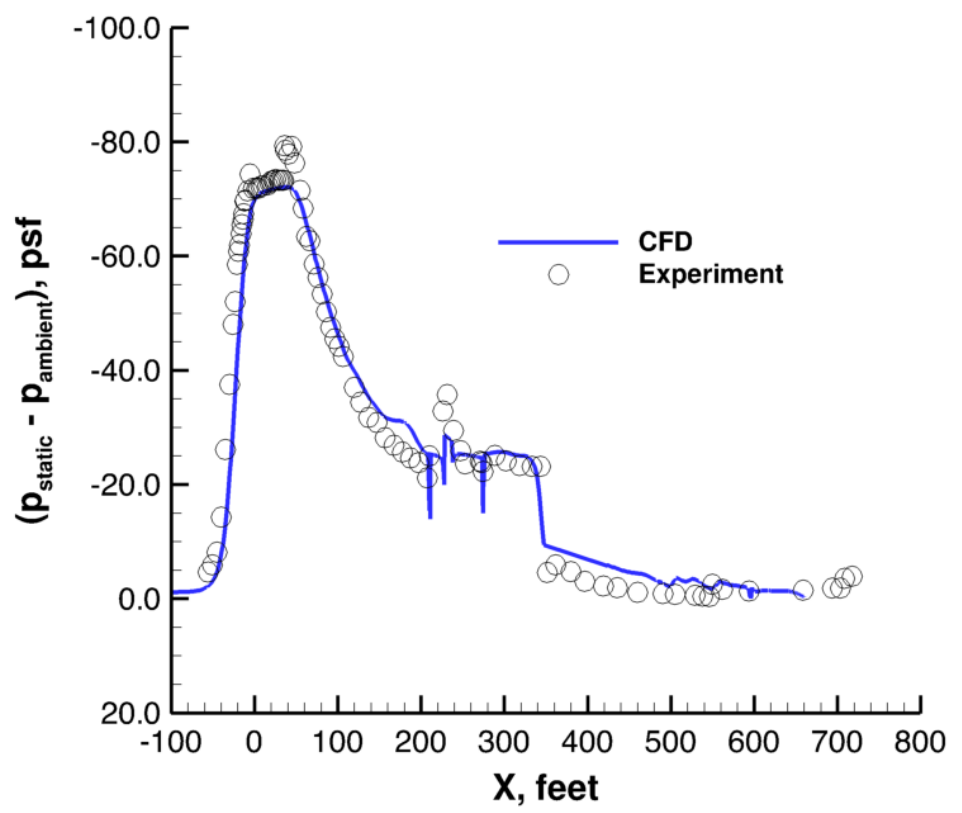

Figure 17 Static pressure distribution on the centerline of the entire tunnel circuit, $\mathrm{q}=68.69 \mathrm{psf}$

\section{H. Turbulence Models}

Figure 18 compares velocity profiles obtained with two turbulence models commonly used in CFD. These models are the one-equation Spalart-Allmaras (SA) model and the two-equation SST model. Note from Figure 18, which depicts the profiles at station 12 (midway through the $3^{\text {rd }}$ diffuser), that the SA turbulence model did not do a very good job at predicting the experimental velocity profiles: the SA velocity profile was considerably more uniform with no reverse flow near the walls. The experimental values were highly skewed toward the outer wall 
with a region of reverse flow near the inner wall. The velocity profile obtained with the SST turbulence model matches the experimental data much better. Although not shown here, similarly poor results were obtained with the SA turbulence model through out the entire tunnel circuit. This is to be expected, as the version of the model used in this study was not designed to predict separated flow behavior.

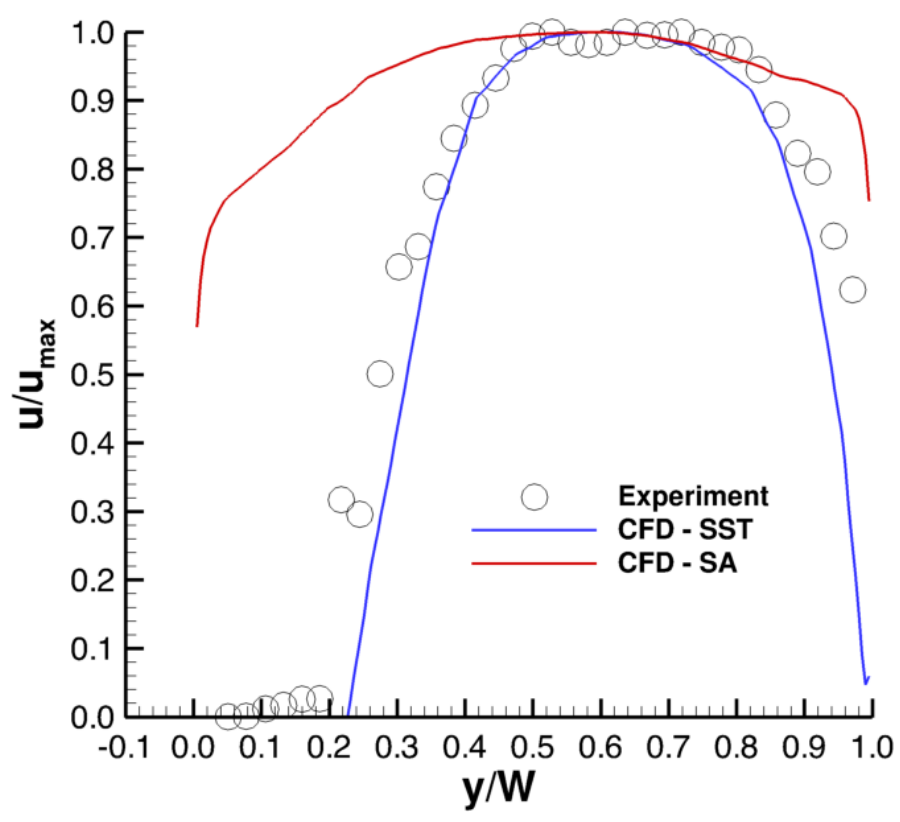

Figure 18 Comparison of turbulence models, horizontal velocity profile, station 12, q = 57.25 psf

\section{Concluding Remarks}

Numerical simulations of the NASA Langley $14 \times 22-\mathrm{ft}$ Low-Speed Wind Tunnel circuit are presented. The geometric model of the tunnel used for the simulations closely matches the structure as it was configured in 1983 to facilitate comparisons with experimental data obtained in the early 1980s when the facility was undergoing studies to improve the flow quality in the tunnel circuit.

The predictions indicate that the flow begins to degrade midway through the $1^{\text {st }}$ diffuser with regions of reverse flow developing on the inner walls of the of the tunnel through the location of the fan drive. The predicted results showed that the flow is skewed towards the outer walls, as observed in the experimental data. The flow in the return leg is shown for general interest only, since many of the geometrical features present in that section of the circuit were not modeled: the actuator disk used to model the fan drive does not include the swirl components, nor the fan support struts were included in the geometric model.

In general, despite the discrepancies in the return leg, the flow behavior within the tunnel circuit follows what was described in the reports published during the effort to improve flow quality in the facility. Thus, simulationbased results like those presented here could be used to understand the deficiencies in circuit flow behavior and design better tunnel modifications.

The simulation effort described in this paper requires additional work. Proper modeling of the fan drive and support struts will require detailed information regarding the fan characteristics. The torque and spatial distribution of the thrust and torque along the fan blade are needed to adequately model the swirl characteristics of the fan. New models for the anti-turbulence screens, grid, and honeycomb are also required. Equally important, experimental facility operators need to be mindful of the type of data required to validate CFD predictions like what is presented here. The authors were fortunate in that experimental data that could be used for this purpose exist for the $14 \times 22$ ft. tunnel. Newer facilities should include flow calibration/diagnostics studies into their schedule for the purposes of code validation.

\section{Acknowledgments}

Funding for this work has been provided through a NASA Phase 1 SBIR. The authors would like to thank William Ball of NASA Langley and Jason Hall of Stinger Ghaffarian Technologies (SGT) for their efforts in 
providing the laser-scanned point-cloud data for this investigation. The authors also extend their gratitude to Judi Hannon, Frank Quinto, and Zachary Applin of NASA Langley for sharing their insights regarding the 14 by 22-Foot Subsonic Wind Tunnel and the facility measurements.

\section{References}

1 AGARDograph 336, Wind Tunnel Wall Corrections, B.F.R. Ewald, (Editor), October 1998.

2 Eckert William T., Mort, Kenneth W.: "Aerodynamic Design Guidelines and Computer Program for Estimation of Subsonic Wind Tunnel Performance”, NASA TN D-8243, October, 1976.

3 King, Christopher D., Olcmen, Semih M., Sharif, Muhammad A. and Presdorf, Tom: "Computational Analysis of Diffuser Performance for Subsonic Aerodynamic Research Laboratory Tunnel”, Engineering Applications of Computational Fluid Mechanics, Vol. 7, No. 4, 2013, pp. 419-432

4 Olander, Mattias: “CFD Simulation of the Volvo Cars Slotted Wind Tunnel”, Masters Thesis 2011:33, Chalmers University of Technology, Dept. of Applied Mechanics, 2011

5 Wall, Anette: "Simulating the Volvo Cars Aerodynamic Wind Tunnel with CFD", Masters Thesis 2013:08, Chalmers University of Technology, Dept. of Applied Mechanics, 2013

6 Bertholds, A.: “CFD Simulations of the New University of Sydney Boundary Layer Wind Tunnel”, Student Paper, Uppsala Universitet, 2002

7 Peter Moonen, Bert Blocken, Staf Roels, and Jan Carmeliet: "Numerical Modeling of the Flow Conditions in a Close-Circuit Low Speed Wind Tunnel”, Journal of Wind Engineering and Industrial Aerodynamics, 94 (2006) 699-723

8 Rumsey, C., Slotnick, J., Long, M., Stuever, R., Wayman, T., "Summary of the First AIAA CFD High Lift Prediction Workshop,” AIAA-2011-939, Jan 2011.

9 Gentry, Garl L., Jr., Quinto, P. Frank, Applin, Zachary T.: “The Langley 14- by 22-Foot Subsonic Tunnel: Description, Flow Characteristics, and Guide for Users” NASA TP-3008, September, 1990.

10 Applin, Zachary T.: "Flow Improvements in the Circuit of the Langley 4- by 7-Meter Tunnel," NASA TM 85662, December 1983

11 Barna, Stephen P.: "Experimental Investigations on the V/STOL Tunnel at NASA/Langley Research Center," NASA CR 165655, February 1981

12 Nayani, Sudheer N., Sellers III, William L., Brynildsen, Scott E., Everhart, Joel, L.: "Numerical Study of the High-Speed Leg of a Wind Tunnel”, AIAA Paper 2015-2022, 53rd AIAA Aerospace Sciences Meeting, 5-9 January 2015, Kissimmee, FL

13 Frink, N. T., Pirzadeh, S. Z., Parikh, P. C., Pandya, M. J., and Bhat, M.K.: "The NASA Tetrahedral Unstructured Software System,” The Aeronautical Journal, Vol. 104, No. 1040, October 2000, pp. 491-499

14 Samareh, J. A.: "GridTool: A Surface Modeling and Grid Generation Tool", Proceedings of the Workshop on Surface Modeling, Grid Generation, and Related Issues in CFD Solutions, NASA Lewis Research Center, Cleveland, OH, NASA CP-3291, 1995, May 9-11, 1995

15 Pirzadeh, S. Z.: “Three Dimensional Unstructured Grids By The Advancing Layer Method,” AIAA Journal, Vol. 33, No. 1, 1996, pp. 43-49

16 Lohner, R. and Parikh, P., "Three-Dimensional Grid Generation By The Advancing Front Method," International Journal for Numerical Methods in Fluids,” Vol. 8, Issue 10, 1988, pp. 1135-1149

17 Menter, F. R. (1993), "Zonal Two Equation k- $\omega$ Turbulence Models for Aerodynamic Flows", AIAA Paper 932906. 